\title{
Career Gains and Identity Loss: The Effects of English in the Nepali Hinterlands
}

\author{
Ashok Raj Khati
}

\begin{abstract}
English in developing countries like Nepal has played a crucial role in increasing career and economic opportunities. It has provided access to the information and networks that are vital in building and maintaining economic links. On the other hand, there is an emerging issue of its threat to the local languages because of the massive use of English in different spheres of Nepalese lives. The major focus of the article is on how English has become instrumental in creating opportunities among multilingual communities and what perception these communities hold towards English and the development of local languages by incorporating the perspectives of EFL teachers from multilingual backgrounds and researcher's own understanding of the context. The paper argues that English has unquestionably become instrumental in promoting career and economic opportunities, and the foremost reasons behind the decline of many local languages are more of political, cultural and economy guided in nature.
\end{abstract}

Key word: English as a global language, Local language, EFL (English as foreign language) teachers, Linguistic identity, Multilingual community

\section{Introduction}

I face students from various ethnolinguistic backgrounds at post secondary level, in which I have been assigned to facilitate English as a compulsory course. The students are primarily from Magar, Newar, Tamang, Hayu, Pahari, Sunuwar and Majhi communities. Their cultural and linguistic backgrounds not only reflect their identity but also the diversity in language, art and literature. In fact, I have been observing for a decade that these groups of students are not highly interested in their native languages and culture. Children, for example, from Hayu, Pahari, Majhi and many other marginalized communities in Ramechhap, often seem to have forgotten their mother tongues because of the dominant role of Nepali and English in every sector (Khati, 2012), neither are they enthusiastic to learn their mother tongues. The trend of not using mother tongue, not only in wider social contexts but also at home, is increasing among the young indigenous/ 
tribal and marginalized (ITM) people due to the dominant role of Nepali and English in mass media and education (Sonntag, 1995; Eagle, 1999 cited in UNESCO report, 2011). It seems as if a whole generation will fail to recognize and transfer this distinct linguistic property of Nepal into the next.

English has already entered into different domains of Nepalese lives. It is no longer limited to the classroom situation in Nepal. It has now expanded its reach to various fields such as democracy, media, international politics, commerce, human rights, diplomacy, tourism and development sector. The craze for English education in Nepal has been growing. There are famed publishing houses, textbooks in English by Nepali writers and editors, training centres, different teams of writers, translators, trainers all promoting English, all engaged in English language teaching (ELT) enterprise, government schools shifting their medium of instruction (MOI) (Bhattarai and Gautam, 2005). English has become a principle component of the Nepali education system. Two key forces: globalization and neoliberalism - have contributed in this regard. The number of multinational companies and international nongovernmental organizations is increasing these days due to Nepal's membership in various international organizations such as the World Trade Organization, the World Bank, and the United Nations (Phyak, 2012).

Further, English has become a medium of communication among the younger generation. There is the use of hybrid of language and culture; many users make use of 'broken' English in their every day lives. Private English medium schools are able to make sale of English. They have associated English with quality education. Nepali parents are enticed with English language, even if there are government-funded schools nearby them that provide free education at school level. Moreover, many community schools in Kathmandu Valley and outside have already shifted their MOI to English primarily to increase the number of students and to compete with private English medium schools and the trend is mounting (Khati, 2013). Youngsters use English massively while using cell phones, Internet, and Facebook, Twitter and the like social networks. They are greatly influenced by mass media, technology and foreign culture. These elements give them positive motivational orientation towards learning English language. So it is very important to explore and analyze the changing position of English in the multilingual community of Nepal in relation to career promotions and development of local languages.

\section{The Study}

English is at the heart of the globalizing world, disrupting local language hegemonies, not uniformly, but in ways that are unique to specific geo-political entities, and unpredictable in effect. "...creating new opportunities for some while closing off opportunities for others," (Farell and Giri, 2011). The role of English in a globalized world is debated where English might create both social cohesion and social division. This

$78 \quad$ Journal of NELTA, Vol 18 No. 1-2, $\quad$ December 2013 
study attempts to address two important questions: 1) How do EFL teachers explain the advantages of English as a global language in creating more career and economic opportunities? 2) What is the perception of these teachers of English as a global language to the development of local languages? To answer these questions the author has conducted a focus group discussion with seven EFL teachers. The researcher has attempted to interpret their experiences, perceptions, attitudes and beliefs along with the researcher's own understanding of the multilingual context of Nepal.

\section{Background to the participants}

Participants were included from five linguistic backgrounds: Magar, Newar, Hayu, Pahari and Tamang. Among seven participants, five were male and other two were female. They speak Nepali as a second language. Four of them have completed bachelor's in education and three of them have master's degrees from Tribhuvan University. All participants have specialized in English language education and are now working in the capacity of EFL teachers in Ramechhap and Kathmandu. They are associated with their native language associations (LA) in different capacities and partly they also bear managerial profiles in various schools, colleges, professional associations and non-government organizations. A few of them lack the exposure of their native languages but all participants use Nepali and English for different purposes. I have particularly chosen these participants for three reasons: 1) they were EFL teachers who could understand the scholarship of English as a global language in developing countries like Nepal; 2) they were from ITM language communities that help them to reflect on their own ethnolinguistic identity; and 3) they had strong sense of multilingual community as they bore different organizational and managerial profiles in Nepal.

\section{Focus group discussion}

The three-hour focus group discussion and their responses were recorded using notes, as there were two assistants who made note of their responses. The researcher moderated the discussion. He made further inquiry by telephoning in some cases to elaborate a few assumptions they made during the discussion. The focus group discussion was chosen to draw upon participants' attitudes, feelings, experiences, reactions and differences in opinions towards the use of English language and to explore the degree of consensus on the topic which may be well revealed through the social interaction. It also assisted the researcher to gain a larger amount of information in a shorter period of time.

\section{Procedures}

This researcher has a long professional engagement with these participants in different circumstances in the past. It was not difficult to seek consent from them. They were informed about the purpose of the research project a month earlier. All of them agreed. A consensus was made to make the participation of all in FGD in Kathmandu when the participants from Ramechhap had an 
occasion to come to attend the program of Teachers' Union of Nepal (TUN). They were informed to come to Kathmandu University (KU) at Balkumari, Lalitpur. It was easier for me in a way that other participants from Kathmandu valley were involved in KU. They were not provided details about the research project earlier but they were made aware about the area and the purpose of the study we were going to discuss.

\section{Results}

The result of collected data is presented in two broad themes.

\section{English for career enhancement}

In a way English has been viewed as a tool of empowerment and advancement globally. More than half of all imports and exports are conducted through transactions between local companies and their foreign affiliates. Companies are increasing their geographical outreach and there are more mergers and joint ventures. Coleman (2011) attempted to identify some of the roles that English plays in development contexts. He identified four broad areas where there is evidence that English makes a contribution: increasing employability, facilitating international mobility (migration, tourism, studying abroad), unlocking development opportunities and accessing crucial information. And the fourth contribution is the acting as an impartial language in contexts where other available languages would be unacceptable. Norton and Tembe (2011) have carried out a study on 'English education, local languages and community perspectives in Uganda' in an African context. The study was more focused on the local language policy in rural primary schools and perspectives of community towards the policy. However, the study shows that English language is necessary for international communication and economic opportunities and highlights the multilingual policy of Uganda.

Though Nepali is an official language and it serves as a lingua franca in various sectors in Nepalese society, people encounter English in different official purposes in Nepal. Many project proposals are written in English in several government and other nongovernmental organizations, for example. Similarly, people from multilingual communities are highly attracted towards private English medium schools and send their children to those schools. They do not seem to have much concern with their own local languages. One of the participants from a Pahari language community articulates his views in the following ways:

I love the English language. At my workplace Nepali is used extensively, however, there are many documents in English that I have to deal with. At home I have to support my children in their homework in English and other subjects. I have enrolled them in an English medium school. English has some bonus advantages in building networks, communication, and career options at national and international levels. I cannot think of my profession without English. English is an added and preferable qualification for me and many other professionals. I can shift my profession in no time because I have English language in my hand. 
He seems to be confident enough for opting for any professions with his English qualification in the days to come. In Nepal, the majority of job announcements do not miss the requirement of fluent spoken and written English. In schools there is a high demand of 'energetic', 'dynamic', 'self motivated', qualified and trained EFL teachers particularly in English medium ones in Nepal. Generally, English graduates can survive at ease by teaching English in schools and colleges. Another participant from the Magar linguistic background replied in this way:

English has created direct benefits to me. There is a high demand of English teachers in my community. Beside at my workplace, I teach English to the children in my free time. They pay for these classes instead. Further, I have maintained a good network with friends, professional associations through using email, Internet, websites that mostly take support of English. English has assisted me to make effective communications in wider community. I often download the books, articles, read English newspapers, play games, watch movies and other materials in English at home. For me English has been a major skill.

Many students especially from government funded schools and colleges seem to be low achievers in English and they join extra classes, which become a good economic source for EFL teachers in Nepal. In others cases, English has opened the doors to the world. A participant whose mother tongue is Hayu put his views differently in terms of local languages, Nepali, English and the global economy:
I do not use English much in my daily life, neither have I encountered the occasions when I felt I should have possessed native like English. English has not created any economic benefits for me. Many youngsters are attracted with English because of its use at wider social context. In my every day life there are a very few occasions when I encounter English such as while reading notices, advertisements, letters and labels of goods at my shop. I do not see English can only enhance economic and career benefits. The scholars who have very deep knowledge of Sanskrit, Hindi, Maithali, Nepali and other languages of the East are engaged in reputed Western Universities. They are enjoying highly sophisticated and prestigious lives there.

He maintains that English of the western world is not only the reason for economic advancement and gives more emphasis on eastern language and knowledge. He further elaborates his views in following ways:

On the other hand, you can see, the youths in Nepal are attracted towards learning Korean and Japanese languages nowadays to go to Korea and Japan for economic opportunities. I do not believe that it is only English, which is generating income in our lives. In fact global economy fluctuates, and we regard and discard the languages accordingly.

It indicates that the world economy determines the spread of English as a global language and use of other regional and national languages. In fact, economic globalization relies on English speaking population; at the same time it produces the same population all over the world. In Nepal 
many youths are learning Korean, Japanese and other European languages for lucrative jobs and more financial opportunities. Next view of English as a global language is associated with 'prestige' and social 'status' in Nepal. In this respect, another participant plainly expressed that:

Though my mother tongue is Newari, my day usually starts with English and ends with English medium private school and college. My exciting schedule in each day is the result of my English. English has secured my career and granted me an economically sound life. Moreover, English has been instrumental to give me a status of scholarly personality in the Nepalese multilingual context. Hence, it can be said that English is flourishing as the most fascinating and advantageous language especially among indigenous language speakers in Nepal. It has made an easy access of those speakers to the international language community.

She seems to be satisfied with her everyday life and her status with English.

\section{English and local languages in Nepal}

The spread of English is a controversial issue and cannot be fully understood without the realization of the hegemonic and imperialistic nature of English. It has also shown that English is unilateral in vision and poses a real threat to other languages and cultures. The majority of North Amerindian and the Australian Aboriginal languages fell victim to predominantly by English. It was true that when English was introduced to academic life, it caused
Latin and Greek to vanish from the curricula of schools and universities (Crystal, 2003). In South Asian scenario, Nunan, (2003) has carried out a study on the impact of English as a global language on educational policies and practices in the Asia Pacific region. The study is more focused on policy review and practice on-the-ground. However, it has partly attempted to address the impact of English education on first language / indigenous language development. The result shows that English has been commodified in many countries and to some extent many governments are not serious about the effects of the market-oriented economic ideology of English language education.

Nepal is home to over 100 languages, many of which are now endangered. Languages spoken for generations may soon be extinct. There is a great a debate over the role of English to the development of local languages of Nepal. Some argue that English has expanded a cultural domination of the western world in Nepal and it has displaced the local languages of Nepal; others argue that it is not true. They view that other factors like urbanization, intergeneration language transfer in which parents are reluctant to teach their mother tongue to their children and dominant role of Nepali language have a greater impact on the loss of these languages. Anthropologist and linguist Mark Turin, who spent many years in eastern Nepal, documenting Thangmi language, one of the world's endangered languages, stated to the BBC radio (2012) that there are two reasons that languages become extinct in Nepal. Firstly, the more 
traumatic but less frequent is going through natural disaster was when people die and take their languages with them when they go. The second responsible factor of language loss for Turin is the language shift. When a particular speech community replaces one language, usually a low status language with another, often highly prestigious, in this case their communities live on but their language is lost in their transfer. Turin must be indicating the Nepali language which is considered a prestigious language.

In this case, a popular Nepali comedian, Wilson Bikram Rai, popularly known as Take me Bhudha made an important remark in a TV program regarding the declining flavor of indigenous and minority language:

I have been using हौलाखे (for a while), हौनानी (for a while, my child) and सेबारो (greeting in Limbu community) like terms among Nepali people worldwide through TV and stage programmes not just make them laugh. Once these were not only the expressions of Rai and Limbu but also of people from other communities in eastern hill did use. Gradually the original flavor of these terminologies and local languages disappears. People started using English in the name of modernization, they slowly forgot their own languages, dressing style and ethnicity. In many instances, they feel ashamed of using their own language.

Taking support of Nepali and English, people from multilingual communities are more attracted to master Nepali and English than their own mother tongues. They also feel humiliation in using their own language in many instances. A participant from Hayu language community who is also a member of Hayu society of Nepal, expressed her bitter experience in the following ways:

Sometimes people have strong negative attitude towards minority languages, which are confined at home and are used with the same linguistic group of people. They consider these minority languages have a low prestige and less relevant compared to Nepali and English. Therefore parents do not teach these local languages to their children. This attitude dominates the local languages and causes disappearances. English and Nepali languages are equally responsible in creating cultural inferiority among multilingual speakers in Nepal.

She places her points that growing use of English in many domains and the role of Nepali as an official language, and both languages as the MOI in schools and colleges, make our local language a sideline. In this case she asserted that there is an adverse impact on youngsters of her community. Nonetheless, she mentioned that the government policy is supportive at present for the preservation of local languages and cultures. Regarding the impact of English on the development of local language, another participant said that:

Three years ago, I came to know that I have my own distinct mother tongue: Pahari. Nobody told us, neither was it used at home nor in the society. I do not blame the English language for displacing local languages, it is the Panchayat era in Nepal when one nation and one language policy was promoted for decades. Consequently, illiterate old generation forgot their own 
culture and language, neither were they able to transfer this language to us. They use Nepali and we are grown with Nepali as a first language. The other case is the substantial use of English in governmental and non-governmental organizations at least in written form. We use it for the purpose of documenting reports and proposals, and communicating with wider audience.

He points to the monolingual dogma during the Panchayat System and semi official use of English in offices. Some people see the significance of English and other languages in different local, national and international parameters. In this regard, a participant formulates his views as below:

Entire community uses Magar language in my village. Even the students of the same community speak their own L 1 in schools. I do not see any negative impact of English to the development of local languages. Magar is spoken at home and in the community. Nepali is spoken in outlaying part of the community including schools, markets, offices, district headquarter whereas English is used at national and international level as well as in the higher education.

This researcher has observed that this participant rarely uses the Magar language at home. He does not show any negative attitude toward the English language; instead he denotes that to some extent English has made him open-minded from a take-forgranted cultural dominance in a multilingual context of Nepal, and receive opportunities to enjoy personal interests through English.
A participant opines in a narrative form trying to take a neutral position regarding this issue as below:

Those were the days when I used to feel a high-class citizen when I started learning English alphabets. In high school, some students from Tamang community used to speak in Tamang language, but others used to make fun of them. They used feel inferior among Nepali speaking students. I did not know how I did choose English as a specialization course at post secondary level. I didn't acquire nor I learn Newari language because my parents did not speak and I had no exposure to it. But I don't regret it. If I had Newari language, it would be good, but if I had no English language, my identity would not be such as I have today.

English has made this participant survive and he seems to be satisfied with the status gained by English. But this participant from Newari language background further expressed his dissatisfaction in this way:

English has slightly displaced local languages because children nowadays are starting their foundation of education with English, not with their native languages. This is not a good sign for the development of local languages.

Early grade English and English as MOI policy in education to a greater extent discourage the use of local languages. However, all participants agree that current mother tongue education policy is supportive to promote local languages; a few of them are skeptical about the implementation of the policy in practical grounds. 


\section{Discussion}

In Nepal, many employers use English at their workplaces one way or the other and they send their children to English medium schools where children start their early foundation of education in English. A few of them, such as EFL teachers, start their day and end it with English though many people have very few occasions with English in their everyday life. Likewise, sizable numbers of people from ITM communities were not familiar with their linguistic backgrounds at earlier stage of lives; and nor did they possess their mother tongue. Attraction toward English is intensifying everyday in Nepali hinterlands.

\section{The English effects in career gains}

This study directly shows that English has expanded economic networks, wider communication and more career options. It has also increased the chances of efficiency in different careers and more income. It has become an added and preferable qualification for the candidates to go to the job markets nationally and internationally. In this regard, the study partly affirms with Hasman (2000) who focuses on the role of English on the development of the international marketplace. The study also shows that multilingual speakers even cannot think about their careers without English in many respects. It indicates the vital role of English in different professions.

In this light, at the $15^{\text {th }}$ international conference of NELTA in Kathmandu, Rt. Honourable Chair of the former Constituent Assembly (CA), Mr. Subas
Chandra Nembang made an important remark on the occasion. He made his points as follow:

The importance of the English language has become universal. Undoubtedly, it has been widely used in the present day. Without the knowledge of the English language our access to more than half of the world would become inaccessible. Our ability to communicate with a large part of the world and do business with them would be extremely limited. We will miss all the nice opportunities that more than half of the world offers to us for our all-round development. Therefore, it is not wise not to have good command of English for all of us. Nowadays knowing only one language is not enough for our all-round development. We have to learn more than one language. (Phyak, 2010).

In the similar line, Graddol (2010) at the same occasion indicates that the global spread of English will lead to serious economic and political disadvantages in the future... a future in which monolingual English graduates face bleak economic prospects as qualified multilingual young people prove to have a competitive advantage in global companies and organizations. The privilege of being multilingual speakers in the present day world as well as our relationship with the global community at different levels through the English language is important.

Supporting these two views partly, this study also signifies the implication of the different roles of local, official and global languages in different spheres of one's life, but the study is significantly different in terms of maintaining economic links and opportunities 
through English rather than through fluent multilingual speakers. LarsenFreeman (2007), states that even the functionalism of English contributes occupational, economic privileges that the users of language can get in terms of prosperity. Indeed English is a necessary skill for many guest workers, who leave their home countries in search of better-paying jobs elsewhere. Likewise, in many countries, the money that foreign workers earn and send to their families back home is a significant contribution to the national economy of their home countries. Her voices are found much similar with this study in relation to the role of English for employability in corporate sectors, which Graddol (2010) also affirms.

However, this study indicates that there are some relations of English in building internal relations and exploiting career and economic chances at home. For instance, many teachers in Nepal go to extra ('tuition' and 'coaching') classes where the students are charged extra fees for these classes. Using Internet for other economical, academic and recreational purposes undoubtedly saves time and money. The next revealing fact of this project is that English has undeniably been an asset for multilingual speakers to be a more global citizen in Nepal in which English plays role to promote global networking and communication. Global networking has direct impact in expanding career gains as well as accessing necessary information. The findings of this study matches with Coleman (2011) who identifies some of the roles English makes, for instance, increasing employability and accessing crucial information. To some extent, the study also unfolds two similar points with the study of Norton and Tembe (2011) in which English language has been viewed necessary for international communication and economic opportunities.

Apart from the economic prosperity and economically sound life, the study also supports the point of several earlier studies that English has been viewed a language of higher social prestige since the Rana regime in Nepal. It is still prevalent in many cases that it is the language of elites and rich ones. The rich people, government officials and people from higher classes send their children to private English medium schools or they enroll them in reputed universities of English speaking countries. Only the commoners make their children go to Nepali medium or government-aided schools. Though it is not revealed on the surface, the voices of these EFL teachers further portray that English can be a possible shared asset for multilingual speakers in the days to come, as English is not entirely difficult to afford these days unlike in the past. In this sense, it merely indicates that English can be a lingua franca among multilingual speakers and a solid instrument for social cohesion.

The study adds the points that the better the English language skills, the more the chances of employability. An English speaking workforce seems to be a necessary precondition for effective participation in global economic activities. With reference to information-technology and mass 
media in Nepal, it is observed that the readership of English newspapers is increasing because of access of Internet and transportation facilities in even rural areas. Users of Facebook and Twitter, both of which primarily use English are mounting. In this case, people have increasing access to information and knowledge. At the same time, English has added more and efficient technology users to make their jobs easier and more economical. One does not need to depend on traditional occupations in the multilingual context of Nepal. In education, the traditional trend of teaching and learning is gradually shifting towards virtual classrooms. So there are multiple choices and, of course, flexible ways of attaining learning and enhancing careers.

But this study does not cover the overall prosperity of Nepalese society in terms of the developing tourism sector, role of foreign investment and international organizations like UN, benefiting from large scale developmental and research projects and social mobility. All of these require more English and play a significant role in providing more career and economic opportunities, and well being.

\section{English and identity loss}

The second discussed issue in the study is English and its relationship with the local languages of Nepal. The study entirely shows new facts in this regard. The foremost fact displayed in this research is that English is not a direct threat to the development of local languages. Minority languages are gradually declining in their original flavour because of massive code mixing. Younger people from minority language communities sometime feel humiliated with their own ethnic identity and they use Nepali and English at different social contexts. It ultimately leads to the neglect of their mother languages. This situation does not encourage the preservation of local languages and knowledge. Regarding education, many parents seem to be interested to educate their children in English medium of instruction. In addition, parents want their children to master the official language (Nepali) or the language of wider communication (English) in early grades. Here the study justifies that only the preference for English and Nepali languages marginalized their local languages and there original flavour in speech.

Many educated people do not make any endeavour to learn their native languages as they are enjoying sound economic, prestigious and scholarly lives with English and Nepali. Another revealing fact in the study is the social division created by English between those who can use English fluently and those who cannot. Because of prestige attached to English and Nepali, it creates cultural inferiority among ITM language users using their own mother tongues. In this case, the study indicates the greater impact of Nepali, the official language of a nation-state, on these languages. It was true that in the name of unifying the nation-state, many local languages faced a slow death caused by Nepali language dominance in Panchayat era in Nepal. Obviously, ITM languages have become library 
languages and there are fewer areas of applications of research on these languages, but the study proves that present government policy is supportive for the preservation and development of these languages. Another trend, loosely exposed here in the study, is that there exists a blind attraction toward English language which has generated a hybrid culture among local language speakers. The second part of this study seems to be contradictory in a way that, on the one hand, ITM language users massively use English in everyday lives and they also send their children to English medium schools, but on the other hand they show their dissatisfaction over the declining loss of linguistic and cultural identity, and little or no official status of their languages.

The findings of the effect of English in relation to the development of local languages of Nepal in this study are not similar to previous studies; neither have there been any studies of this particular nature. English as a global language has not co-existed comfortably with other local languages; rather, it has been viewed as a threatening force to many of the languages of the world and to the cultural identity of different people of the world, including such very strong nations as Japan and Germany. But one of the elusive layers of interpretation in this study is that the participants selected for the purpose of carrying out this research project seem themselves to be the factors for spread of English. They enjoy a sound economic life with English, ignoring their ethnolinguistic identity. It can be observed that these ELT professionals are contributing to the growth of English in Nepal in many respects. Phillipson (1992) asserts that language pedagogical practices and language specialists have contributed to the 'hegemony' of English. He states that ELT professionals are one of the key factors, one of "the forces ... which have propelled English forward" (p.6).

\section{Implication of the study}

On a broader scale, the study suggests the urgent need to address the language issues in Nepal in relation to specifying the official role of English. For instance, English may play any (semi) official role in particular areas of economy, tourism, education and science as the traditional EFL model seems to be declining in later years in Nepal. On the other side, to preserve its local linguistic heritage, what roles need to be provided to Nepali and other local languages, is very crucial one. The second important implication of this study might be an impetus to the policy formulation level to enhance the monolingual, bilingual or multilingual language policies in terms of the effects of English on the development of local knowledge and culture.

\section{In teaching, there are two major implications:}

1. Motivational implication: Teachers obviously need to convey the role of English as a global language in terms of career and economic advancement. Students need to be assisted in terms of shaping career goals where instrumental motivation is necessary. Thus, the value of English as a global language and its relation to academic, professional and economic opportunities are very

$88 \quad$ Journal of NELTA, Vol 18 No. 1-2, $\quad$ December 2013 
important to boost motivation to young learners.

2. Inter cultural competence and Glocalising implication: Competence in many languages brings intercultural competence, which is a vital part of modern life. Thus, to make the students interculturally aware, they need to be supported accordingly to make choices to use language resources. In this regard, they could see the role of their own mother tongue, official and global language in different spheres of their lives. Any additional languages can be incorporated in to curricula which ultimately leads to the multilingual model of education. At the same time, if anyone finds a problem with the spread of English, as Larsen-Freeman (2007) states, one could make English work for him or her in Nepal by universalizing and particularizing tendencies, adapting global trends to meet local needs and adjust to local conditions (glocalisation). She further explained that one accepts it as a tool, a key to success not as a risk to local languages; nor dose anyone have to accept a monolingual view of the world. It again implies that teaching and learning of English needs to be focused on both local and universal needs.

\section{Conclusion}

English has been used for more instrumental purposes in the multilingual context of Nepal. It has unquestionably extended economic connections and more chances of employability at home and abroad. English has become a shard language among multilingual speakers around the globe and it has enabled these speakers to explore cultural differences and to create a kind of understanding enriching negotiations and agreement for common prospects. Therefore it has undoubtedly created career and economic opportunities for local language speakers as a part of global community in multiple ways. Likewise, English in Nepal has become an added and preferable qualification for employability and it has provided more access of information and generated wider communication, which is vital for economic opportunities at the national and international level. To some extent, English has made multilingual speakers more open-minded as it makes them enter into the global village. It would be suitable to mention that local languages, Nepali and English have their significant roles in different spheres of the multilingual context of Nepal.

When observing deterioration of linguistic identity of local languages in Nepal, English as global language is not a sole cause. Lack of inter generation language transfer, role of Nepali as an official language, high mobility of latter generations, government's initiative to start English at early grades and English MOI policy have major impact on the linguistic identity issue of these communities. Moreover, due to the prestige attached to English and Nepali language, young people from ITM language communities seem to be reluctant to use their mother tongues. They face cultural inferiority among Nepali and English language speakers. As they have growing attraction toward the English language to attain 
career gains, it does not encourage the development of their own mother tongues. At the same time, because of the hybrid use of local, Nepali and English languages, these communities are losing their original linguistic flavor. Many people and children from local language communities learn and use English for their personal interests such as chatting with people, reading newspapers, watching movies, making social networks and so on which ultimately lead to their own languages sideline. At this point, it can be stated that the declining linguistic identity of many local languages is more political, cultural and economical in nature.

\section{About the author}

Ashok Raj Khati is a teaching assistant at Tribhuvan University Nepal. He has been associated with English language education (ELE) for a decade. Mr. Khati is a former central committee member of Nepal English Language Teachers' Association (NELTA). He also served NELTA in the capacity of branch chair in Ramechhap for two tenures. Currently, he is pursuing his MPhil in English language education from Kathmandu University. His major area of interest includes the scholarship of English as a global language.

\section{Acknowledgements}

I am grateful to two anonymous reviewers for their comments and suggestions to revise this paper. My sincere gratitude also goes to Suresh Gautam, a visiting faculty at
Kathmandu University, for his initial ideas to develop this paper.

\section{References}

Bhattarai, G. R. and Gautam, G. R. (2005). English language teachers at the crossroads. Journal of NELTA, 10, 1-6.

Coleman, H. (2010). English in Development. London: British Council.

Coleman, H. (2011). Developing countries and the English language: Rhetoric, risks, roles and recommendations. In H. Coleman (Ed.), Dreams and realities: Developing countries and the English language (pp. 9-22). London: British Council.

Crystal, D. (2003). English as a Global Language. (Second Edition) Cambridge: Cambridge University Press.

Farell, L. and Giri, R. A. (2011). English education in South Asia: The challenge of Globalisation. In Farrell, Singh and Giri (Ed.), English language education in South Asia: From policy to pedagogy. New Delhi: Cambridge University Press.

Graddol, D. (2006). English next. London: The British Council.

Graddol, D. (2010). English next India: The British Council.

Gaddol, D. (2010). A key speech on 'English in Diversity' at the international conference of NELTA: Kathmandu.

Gughoul, M. R. (2009). Globalization and EFL and ESL pedagogy: Implication. In Mansooret. al. (ed.), Emerging issues in TEFL: Challenges for Asia. Karachi: Oxford University Press. 
Khati, A. R. (2012). When and why mother tongue use in English classroom. Journal ofNELTA, 16, 42-53.

Khati, A. R. (2013, October 8). To speak or not: English in public schools. The Republica, page 9.

Larsen-Freeman, D. (2007).Teaching and learning English: From Ideology to Empowerment. Journal of NELTA, 12, 67-74.

Markee, N. (2010).A key speech on 'English in Diversity' at the international conference of NELTA: Kathmandu.

Norton, B. and Tembe, N. (2011). English education, local languages and community perspectives in Uganda' in African context. In H. Coleman (Ed.), Dreams and realities: Developing countries and the English language (pp. 9-22). London: British Council.

Nunan, D. (2003). The impact of English as a global language on educational policies and practices in the Asia Pacific region. TESOL Quarterly, 37(4), 589613.
Phillipson, R. (1992). Linguistic Imperialism. Oxford: Oxford University Press.

Phyak, P. (2012). The English language in Nepal. The Kathmandu Post. Retrieved on 20 $0^{\text {th }}$ Oct. 2013 from: http:// w w w . ekantipur.com / the kathmandu-post/2012/07/08/ related_articles/the-englishlanguage-in-nepal/236968.html

Phyak, P. (2011). Linking global with local. Webzine of Netal Choutari.Retrived on 22th Octo. 2013 from:http:// neltachoutari.wordpress.com / ?s=linking + global+

UNESCO (2011).Multilingual education in Nepal: Hearsay or Reality? Kathmandu: UNESCO. 